\title{
Nurse-led Field Hospital: A Novel Nursing Innovation During Covid-19 Pandemic
}

\author{
Waranuch Wongjumnong ${ }^{1}$ and Kannika Supachai ${ }^{2 *}$ \\ ${ }^{1}$ TambolTaykoa Health Promotion Hospital, Sam Khok district, Pathumthani \\ Province, Thailand \\ ${ }^{2}$ Chulabhorn Royal Academy, Bangkok, Thailand \\ *Corresponding Author: Kannika Supachai, Chulabhorn Royal Academy, Bangkok, \\ Thailand.
}

Received: December 02, 2021

Published: December 24, 2021

(C) All rights are reserved by Waranuch

Wongjumnong and Kannika Supachai.

\begin{abstract}
The uncontrollable spread of Covid-19 has increased huge new cases of respiratory symptoms, causing a serious shortage of medical equipment, hospital beds, and healthcare workforce worldwide. Focusing on the shortage of hospital beds, field hospitals have been developed to lighten the caseloads from conventional hospitals. Nurse practitioners, who are prepared to promote the health of people in community, play a significant role in managing field hospitals. Although, current studies have shown the extensive scope of nurse practitioners managing clinics especially regarding chronic diseases, field hospitals remain scarce. This article identified a set of activities of nurse-led field hospitals concerning the novel notion of nurse-led services during the Covid-19 outbreak in Thailand based on a community health nurse practitioner's experience.
\end{abstract}

Keywords: Covid-19; Field Hospital; Nurse-led Service; Nurse Practitioner

\section{Introduction}

The continuing Covid-19 pandemic has disrupted public health systems worldwide. The shortage of hospital beds remains a critical phenomenon challenging healthcare professionals. Consequently, one alternative is applying the military concept of providing support and emergency medical attention to affected people during a conflict or natural disaster [1]. Field hospitals have been rapidly implemented by transforming existing large scale private or public venues to serve as temporary hospitals. This novel healthcare management aims to lighten caseloads from conventional hospitals. The major components of field hospitals comprise three attributes, i.e., rapid construction, massive scale, and low cost. In addition, their five functions include isolation, triage, basic medical care, frequent monitoring and rapid referral, and essential living and social engagement [2].

In Thailand, many field hospitals have been temporarily estab- lished by transforming stadiums, plazas, halls, airport cargo buildings, factories, markets, schools, and temple pavilions. Almost all field hospitals have provided isolated accommodation and free medical care for people with mild to moderate symptoms.

Nurses play a key role in managing those nurse-led services especially community health nurse practitioners (CHNPs). In Thailand, CHNPs are prepared during a two-year program and are certified to work as advanced practice nurses (APNs) by the Thailand Nursing and Midwifery Council (TNMC) [3]. They drive and improve the quality of primary health care throughout the country.

A large agricultural market received 867 people with Covid-19 of whom $70 \%$ were Thai citizens and $30 \%$ were migrant workers [4]. A part of the market was suddenly transformed to a field hospital. CHNPs and registered nurses taking responsibility for health in that area were recruited to practice in the field hospital autonomously. The set of activities that they managed are described below. 
Simulate the field hospital as a community

As primary care nurses they simulated the field hospital as a community where people and environment were the major components directly affecting each other. Following clinical parameters, people with Covid-19 were isolated for 14 days to control the disease. Gathering hundreds to thousands of people with different experiences and backgrounds in a field hospital without privacy affected physical and psychological aspects of all concerned. A trusting atmosphere was promoted by ensuring citizens in the community would receive essential life support, security and safety. Moreover, holistic care was provided for all, and environmental health was maintained and managed based on infectious control standards to prevent indoor and outdoor transmission. In addition, community regulations were established and maintained based upon overall commitment and compliance until citizens were discharged from the community.

\section{Empower group leaders}

While caring for the high volume of people with Covid-19, about five nurses took responsibility for each shift. To achieve the mission of ensuring all must remain safe, they managed gender-specific zoning and group identification. The community participation concept was used to reach these goals. Therefore, they empowered leaders for each group as nurse assistants to disseminate health information and perform required routine tasks such as distributing essential life support and monitoring temperature and pulse. Within some groups, leaders were immigrants who demonstrated service-mind skills, were willing to learn new things and could communicate in Thai. Moreover, leaders were trained to use basic medical equipment and record medical data to reduce patientnurse contact time.

\section{Early detection of silent symptoms}

Even people with Covid-19 reported feeling well, but many had low levels of oxygen in their blood. This constituted a silent symptom or early warning sign that nurses must be concerned with and monitor. Normal levels of oxygen are usually $95 \%$ or higher. When pulse oximeter showed the percentage of oxygen was lower than that level, medical care by oxygen therapy was needed. Actions for detecting of silent symptoms early on, showing concern to maintain safety and protect life as well as instituting a referral system to conventional hospitals were prepared.
Use app platform to support communication

When high temperatures up to 40 degrees Celsius were noted, nurses wore full PPE (personal protective equipment) no longer than two hours. To communicate with people with Covid-19 needed communication technology assistance. At present, numerous communication platforms benefitting healthcare systems were created. This mission used line application to support communication among people with Covid-19 and aided nurses to continue communication while maintaining distance. Choosing the best app platform that people could use easily and become familiar with was needed for health benefits during the disaster.

\section{Discussion and Conclusion}

Nurse-led services or nurse-led clinics have been defined based on what nursing management was performed at the sites [5]. Models of nurse-led services are differentiated by degree of autonomy. Nurses may lead services or be a part of nurse-led services under the supervision of a qualified or specifically trained nurse [6].

While nurse-led services have been recognized to reform quality of care, reduce cost, and increase patients' satisfaction of chronic illness worldwide [7-9], nurse-led field hospitals constituted novel nurse-led services during the emergency created by the Covid-19 outbreak. Those actions represented the experience of Thai community health nurse practitioners to manage field hospitals. Nurseled field hospitals require more insights and further research to determine and refine the relevant best practices.

Moreover, learning from Covid-19 pandemic has motivated nurses to prepare and develop competencies for combating debilitating conditions using foresight to contend with mutation variants or novel emerging diseases. Innovation of nurse-led services for those situations remains a major challenge requiring unlimited judgment during this disruptive era.

\section{Bibliography}

1. Bakowswi J. "A mobile hospital - its advantages and functional limitations". International Journal of Safety and Security Engineering 6.4 (2016): 746-754.

2. Chen S., et al. "Fangcang shelter hospitals: a novel concept for responding to public health emergencies". The Lancet 395.10232 (2020): P1305-1314. 
3. Hanucharurnkul S. "Nurses in primary care and the nurse practitioner role in Thailand". Contemporary Nurse 26.1 (2007): 83-93.

4. Bangkok post. "Hundreds of cases found at 2 markets". 20 May (2021).

5. Hatchett R. "Nurse-Led Clinics: Practice Issues". $1^{\text {st }}$ ed. New York: NY Routledge (2003).

6. Khair K and Chaplin S. "What is the nurse-led service? a discussion paper". Haemophilia Practice 4.1 (2017): 1-4.

7. Carey N and Courtenay M. "A review of the activity and effects of nurse-led care in diabetes". Journal of Clinical Nursing 16.11c (2007): 296-304.

8. Randall S., et al. "Impact of community-based nurse-led clinics on patient outcomes, patient satisfaction, patient access and cost effectiveness: a systematic review". International Journal of Nursing Studies 73 (2017): 24-33.

9. Ohr SO., et al. "Nurse-led normalized advance care planning service in hospital and community health settings: a qualitative study". BMC Palliative Care 20 (2021): 139.

\section{Assets from publication with us}

- Prompt Acknowledgement after receiving the article

- Thorough Double blinded peer review

- Rapid Publication

- Issue of Publication Certificate

- High visibility of your Published work

Website: www.actascientific.com/

Submit Article: www.actascientific.com/submission.php

Email us: editor@actascientific.com

Contact us: +919182824667 